\title{
Different Caregiver, Different Collaboration
}

Helle Rønn-Smidt, MS

University of Aalborg, Copenhagen, Denmark, and Hammel Neurorehabilitation and Research Centre, Aarhus University, Hammel, Denmark

Janet K. Shim, PhD

University of California, San Francisco, San Francisco, California, United States

Amber Fitzsimmons, DPTSc

University of California, San Francisco, San Francisco, California, United States

Kristian Larsen, $\mathrm{PhD}$

Aalborg University, Copenhagen, Denmark

Hanne Pallesen, $\mathrm{PhD}$

Hammel Neurorehabilitation and Research Centre, University of Aarhus, Hammel, Denmark

Contact: $\underline{\text { helsmi@rm.dk }}$

\section{Abstract}

The quality of the collaboration between health professionals and caregivers is of great significance to outcome and recovery. Severe brain injuries after a stroke can leave patients unable to communicate their needs and wishes with health professionals, in which case the role of the caregiver(s) becomes even more important. This position is highly differentiated, and there are substantial variations in how caregivers participate in the collaboration. Using the Bourdieusian concept of cultural health capital, we aimed to develop a broader understanding of the role played by the patient's caregiver and how inequality is produced in the encounter with professionals. This qualitative study was conducted from 2014 to 2018. We observed the meetings and interactions between caregivers and health professionals during patients' neurorehabilitation after a stroke, and we interviewed caregivers and health professionals on their experiences during this period. Constructing three different caregiver types-the proactive, the persistent, and the deferential-we discovered different ways of interacting and different attitudes related to cultural health capital, which provided the caregiver with more or fewer opportunities to participate in a dialogue and negotiation on behalf of the patient.

Keywords: caregiver; collaboration; cultural health capital; neurorehabilitation

Date Submitted: March 1, 2019 | Date Published: April 14, 2020

\section{Recommended Citation}

Rønn-Smidt, H., Shim, J. K., Fitzsimmons, A., Larsen, K., \& Pallesen, H. (2020). Different caregiver, different collaboration. Journal of Social, Behavioral, and Health Sciences, 14, 68-86. https://https://doi.org/10.5590/JSBHS.2020.14.1.06

A special thank you goes to the patients, their families, and the health professionals who took the time and trouble to participate in this research. The study was funded by Aalborg University, Hammel Neurorehabilitation and Research Centre, and VIA University College, Denmark. 


\section{Introduction}

The onset of a stroke generally marks the starting point of a multifaceted rehabilitation process. According to the Danish National Patient Registry, approximately 22,000 people suffer an acquired brain injury annually in Denmark (National Board of Health, 2011). Many of these $(n=12,500)$ are hospitalized and diagnosed with stroke (Flachs et al., 2015; Kompetencecenter for Epidemiologiog Biostatistik Nord, 2014). Developments in treatment over the years have considerably improved outcomes for acute stroke patients, and of the many patients who survive acquired brain injury and stroke every year, only around 1,00o suffer from a resultant severe brain injury (measured by days of hospitalization; National Board of Health, 2011). Although this number is relatively small, treatment and rehabilitation of these patients can present challenges for health professionals (Pallesen, 2014), including specific issues related to the collaboration between the patient, the caregiver(s), and the professionals.

According to a review from 2011, few existing studies have focused on the group of people with the most severe brain injuries (National Board of Health, 2011). Brain injury severity is determined based on the Glasgow Coma Scale (Teasdale \& Jennett, 1974), which assesses impairments related to eye opening and verbal and motor response. A patient with a low-level response is unable to participate actively in their own care and thus having a caregiver to represent them is crucial to a successful outcome for the patient (Lauvli Andersen et al., 2016; Östlund et al., 2016; Sagbakken et al., 2017).

In the current study, the term "caregiver" can represent a spouse, partner, parent, child, blood relative, close friend, or individual with power of attorney. This person may or may not be the patient's legal next of kin. Additionally, we define "collaboration" based on the interprofessional collaborative practice literature aggregated by the National Center for Interprofessional Practice and Education (2018) in the United States. This organization takes its cue from the World Health Organization (2010), who defines interprofessional collaborative care/practice as "when multiple health workers from different professional backgrounds provide comprehensive health services by working with patients, their families, carers (caregivers), and communities to deliver the highest quality of care across settings" (p. 13; see also National Center for Interprofessional Practice and Education, 2018; The Centre for the Advancement of Interprofessional Education, 1987). We further define comprehensive collaborative care as involving aspects of both communication (i.e., dialogue) and negotiation. However, it is important to note that the occurrence of collaborative care as it takes place between healthcare professionals, patients, and caregivers is often not obvious. Therefore, in the context of the healthcare professional-caregiver dyad, the collaborative strategies relied upon and investigated in this study are often implicit and observed rather than explicitly discussed.

Several studies have recognized the importance of this collaboration, and they often focus on communication as an important factor in the professional encounter. They show that good communication is essential to successful collaboration between patient, caregiver, and health professionals (O'Keeffe et al., 2016; Oliveira et al., 2012; Östlund et al., 2016; Thornquist, 2011). Ideally, the healthcare system regards both patient and caregiver as having autonomy, subjectivity, and agency (Sullivan, 2003), thus legitimizing their communication with healthcare professionals and their role in the patient's ongoing treatment. Other studies have shown that communication is vital to shared decision-making (Altin \& Stock, 2016; Cloninger, 2011) and that positive communication provides greater patient and caregiver satisfaction (Altin \& Stock, 2016; Arbuthnott \& Sharpe, 2009). Lastly, communication furthers patients' and caregivers' perception of control over health decisions, their health literacy, and their trust in the provider (Gabay, 2015; Wynia \& Osborn, 2010).

Despite the focus on the importance of communication in clinical settings as well as in research, communication challenges still exist in practice, for a couple of reasons. For one, health professionals often face a scarcity of resources, including time, attention, and communication skills (Formosa, 2015; Gabay, 
2015). Additionally, clinicians sometimes use terminology or medical jargon that can be unfamiliar to patients and caregivers, so healthcare professionals are often required to "translate" this language for laypeople (Khabarov et al., 2015).

Compounding these communication challenges, a patient with a severe brain injury might not be able to plead their cause themselves, express their needs or wishes, or make decisions. In this case, a caregiver may take on the role of speaking for the patient. In addition to the information that the health professionals need and seek, however, caregivers may also wish to communicate patient-related information that health professionals do not necessarily value. Based on the existing research, we argue that there is a need to investigate how these discrepancies between what is valued by the caregiver and by the health professional are not only recognized as related to the caregiver's specific resources, but also how they are actually produced in a much more complex interaction between capital, habitus, and field. Lindhardt (2008) pointed out that there seems to be an unwritten set of rules for how caregivers should communicate, and if they fail to follow these implicit expectations, they may be labeled as "difficult" or "troublesome."

\section{Theoretical Position}

In this study, we argue that collaboration is more than communication skills. We are inspired by the concept of cultural health capital (CHC), elaborated upon by Shim (2010), who defined it as "a repertoire of cultural skills, verbal and non-verbal competencies, attitudes and behaviors, and interactional styles, cultivated by patient and clinician alike, that, when employed, may result in more optimal healthcare relationships " (p. 1). This was further elaborated by Dubbin et al. (2013), who showed how specific cultural interactional styles, skills, and behaviors become capital that is valued and leveraged as an asset by both patients (and, by extension, caregivers) and providers in clinical encounters.

The theory of CHC was derived from Bourdieu's $(1977,1986)$ theories of field, positions, capital, and habitus. Specifically, the professional encounter is situated in a field (in this case, medical), which holds embedded, and often implicit, logic, values, and rules. These form the field's doxa and define which positions are available. In this study, the focus is on the positions of the health professional (doctor, physiotherapist, nurse, occupational therapist), patient (with a severe brain injury following a stroke), and caregiver (spouse or adult children). Depending on the field, certain strategies become possible and desirable, transforming into capital that supports collaboration during the professional encounter. Other strategies become less possible or even inappropriate. The strategies are not calculated or planned by the involved agents; they are more the result of a practical sense that is accumulated through acting in the field (Bourdieu, 1980). This practical sense, which both caregiver and health professional develop as a result of their social interactions (Bourdieu 1986), is referred to as bodily habitus and is more specifically defined as "durable yet malleable sets of dispositions which people acquire, mainly through the internalization of their external world, as part of the process of socialisation" (Crawford \& McKee, 2018, p. 186). Accordingly, those capabilities recognized as resources are not neutral or eternal but are conceived as capital only in relation to a specific field.

A review of existing literature demonstrates that many scholars have found the concepts of economic, social, and cultural capital useful in understanding inequality in healthcare. Abel (2008) showed how culture-related factors, such as knowledge, normative beliefs, and behavior, are associated with people's health status, health changes, and choices. Other researchers (Gagné et al., 2015; Missinne et al., 2014; Oncini \& Guetto, 2018; Pinxten \& Lievens, 2014) have corroborated this finding. Collyer et al. (2017) also showed how Bourdieu's notions of capital, including cultural capital, can elucidate both patients' and providers' navigation of and choices in healthcare.

CHC has been shown to be efficient in explaining inequality in healthcare (Madden, 2015, 2018; Sudhinaraset et al., 2016), and CHC-based studies show how stereotyping and stigma can be produced (Chang et al., 2016; James-Hawkins, 2014). The combination of resource scarcity on the health professional's side and the 
challenges associated with medical terminology impacts caregivers differently, with the result that the professionals view some caregivers favorably while interpreting others as caregivers with "few resources" (without clarifying what that exactly means) or as caregivers who are difficult and demanding (Chung, 2013; Lindhardt, 2008). Health officials state that the involvement of caregivers in rehabilitation is very important (Ministry of Health and Health Promotion, 2015), but there is a gap between this ideal and the actual practice (Lindhardt, 2008).

\section{Objective}

Based on the concept of $\mathrm{CHC}$, this study aims to investigate how inequality is produced in the interactions between caregiver(s) and providers and how this seems to define and characterize the collaboration as either "easy" or "difficult." Although we did not examine the exact benefits of using capital, we did identify the issues that lead to a caregiver being positioned as a reputable relative in the caregiver-health professional collaboration in neurorehabilitation. In other words, we investigate how $\mathrm{CHC}$ can be used to "grease the wheels," becoming the oil or lubricant that makes the collaboration go more smoothly. Using CHC is not so much a deliberate strategy employed to make gains in healthcare interactions: It is often used much more intuitively and unconsciously, thus creating (or failing to create) the experience of a smooth flow of interactions (Shim, 2010). This study argues that the shared experience of flow and ease has a positive influence on the rehabilitation process, and therefore the influence of $\mathrm{CHC}$, as a form of capital that the caregiver can use to produce this sense of ease in the interaction with health professionals, becomes highly significant.

\section{Method}

This study was designed as a qualitative study investigating how the encounter between patients, caregivers, and health professionals during rehabilitation after stroke influences the rehabilitation process.

Methodologically, the study was inspired by the constructivist approach to grounded theory, developed by Kathy Charmaz (2014). The theory provides a framework for qualitative research when the focus is on learning about the worlds and people we study. Grounded theory assumes that social reality is multiple, processual, and constructed. Charmaz stated that no qualitative method is solely inductive and that grounded theory should be considered more as a set of guidelines to steps in the research process. In that sense, it can complement rather than oppose other approaches to qualitative data analysis (Charmaz, 2014).

\section{Inclusion of Patients, Caregivers, and Health Professionals}

Six patients diagnosed with severe brain damage after stroke were included in this longitudinal study, which followed patients throughout their rehabilitation process. Four patients were followed longitudinally for 2732 months, starting after the first acute phase when they were admitted to a hospital (in the western part of Denmark) for neurorehabilitation immediately after the acute phase of the stroke. After the first analysis, two additional patients were included to further saturate the data. These were followed for only 3 months (see Table 1) due to the project's deadlines. All patients (where possible) and caregivers were informed of the study verbally and in writing, and formal consent was collected from the participants. The study was approved by the Danish Data Protection Agency. 
Table 1. Study Participants and Data

\begin{tabular}{|c|c|c|c|c|c|c|c|}
\hline \multirow[b]{2}{*}{ Caregivera } & \multirow[b]{2}{*}{ Patient $^{\mathbf{a}}$} & \multirow[b]{2}{*}{ Sequelae at hospital admission } & \multirow[b]{2}{*}{$\begin{array}{c}\text { Data } \\
\text { collected }\end{array}$} & \multirow[b]{2}{*}{$\begin{array}{c}\text { Interviews } \\
(N=\mathbf{2 8})^{b}\end{array}$} & \multicolumn{3}{|c|}{ Observations } \\
\hline & & & & & $\begin{array}{l}\text { Meetings } \\
(N=12)^{c}\end{array}$ & $\begin{array}{l}\text { Clinical } \\
(N=\mathbf{3 8})^{\mathrm{d}}\end{array}$ & $\begin{array}{l}\text { Informal talks } \\
\qquad(N=60)^{\mathrm{e}}\end{array}$ \\
\hline $\begin{array}{l}\text { John, husband, } 57 \text {, } \\
\text { building } \\
\text { constructor }\end{array}$ & $\begin{array}{c}\text { Elin, wife, } 52, \\
\text { preschool teacher }\end{array}$ & $\begin{array}{c}\text { Severe brain injury, low } \\
\text { consciousness; no verbal } \\
\text { communication or voluntary } \\
\text { functions }\end{array}$ & $\begin{array}{l}\text { May } 2015 \text { to } \\
\text { November } \\
2017\end{array}$ & 5 & 4 & 8 & 15 \\
\hline $\begin{array}{l}\text { Jane, wife, } 69 \text {, } \\
\quad \text { retired secretary }\end{array}$ & $\begin{array}{l}\text { Joe, husband, } 64, \\
\text { retired teacher }\end{array}$ & $\begin{array}{l}\text { Severe brain injury, conscious but } \\
\text { quickly exhausted; limited verbal } \\
\text { communication and limited } \\
\text { voluntary functions }\end{array}$ & $\begin{array}{c}\text { June } 2015 \text { to } \\
\text { January } 2018\end{array}$ & 3 & 3 & 12 & 16 \\
\hline $\begin{array}{l}\text { Chris, husband, } 55 \text {, } \\
\text { factory worker }\end{array}$ & $\begin{array}{l}\text { Rose, wife, } 54 \text {, on } \\
\text { early retirement }\end{array}$ & $\begin{array}{l}\text { Severe brain injury, conscious but no } \\
\text { verbal communication; limited } \\
\text { voluntary functions }\end{array}$ & $\begin{array}{c}\text { July } 2015 \text { to } \\
\text { January } 2018\end{array}$ & 3 & 3 & 5 & 10 \\
\hline $\begin{array}{l}\text { Mary, daughter, 52, } \\
\text { counselor }\end{array}$ & $\begin{array}{l}\text { Eve, mother, } 77, \\
\text { retired nurse }\end{array}$ & $\begin{array}{l}\text { Severe brain injury, conscious, little } \\
\text { verbal communication; limited } \\
\text { voluntary functions }\end{array}$ & $\begin{array}{l}\text { June } 2017 \text { to } \\
\text { August } 2017\end{array}$ & 1 & 1 & 2 & 4 \\
\hline $\begin{array}{l}\text { Adrian, son, } 49, \\
\text { accountant }\end{array}$ & $\begin{array}{l}\text { Allan, father, } 78, \\
\text { retired farmer }\end{array}$ & $\begin{array}{l}\text { Severe brain injury, conscious, no } \\
\text { verbal communication; limited } \\
\text { voluntary functions }\end{array}$ & $\begin{array}{l}\text { June } 2017 \text { to } \\
\text { August } 2017\end{array}$ & 1 & 1 & 2 & 4 \\
\hline $\begin{array}{l}\text { Jim, husband, } 56 \text {, } \\
\text { train conductor }\end{array}$ & $\begin{array}{l}\text { Liza, wife, } 56 \text {, } \\
\text { social worker }\end{array}$ & $\begin{array}{l}\text { Severe brain injury, conscious but } \\
\text { quickly exhausted; limited verbal } \\
\text { communication and limited } \\
\text { voluntary functions }\end{array}$ & $\begin{array}{c}\text { December } \\
2015 \text { to } \\
\text { January } 2018\end{array}$ & 3 & o & 9 & 11 \\
\hline
\end{tabular}

Note. Also included were 12 health professionals ( $n=2$ male and 10 female), all of whom specialized in neurorehabilitation ( $n=3$ nurses, 2 occupational therapists, and 7 physiotherapists), each with 3-14 years of experience in working with stroke patients.

a To protect the participants' identities, all names are pseudonyms. ${ }^{\mathrm{b}} 60-120 \mathrm{~min}$ each. ${ }^{\mathrm{c}} \sim 60 \mathrm{~min}$ each. ${ }^{\mathrm{d}} 60-240 \mathrm{~min}$ each. ${ }^{\mathrm{e}} 10-15$ min each. 
At the beginning of the rehabilitation process, the included patients all had a low consciousness, absent verbal language, and little to no voluntary motor or eye functions. We purposefully selected the caregivers of these six patients with severe brain injury for inclusion in this article because they had a special role in the rehabilitation process because they substituted for the patients, who could not actively speak or engage for themselves. Furthermore, we included 12 health professionals, all of whom interacted significantly with the six patients and were the primary point of contact for them throughout their rehabilitation.

\section{Interviews and Observations}

The current study is based on data obtained through observations of the meetings and interactions between caregivers, patients, and professionals, and through interviews with the six caregivers and 12 health professionals.

The semistructured interviews were conducted in a private room at the clinic. The questions directed at the caregivers concerned the patient but also how the caregivers experience their role, including the challenges and successes, where they find support, and their collaboration with the health professionals. Lastly, the caregivers were asked what advice they would pass on to other caregivers in similar situations.

The health professionals were questioned, for instance, on how they would describe the patient and the caregiver and how they experienced the actual collaboration. Then, they were asked to describe what they thought made it easy/difficult to collaborate with the caregivers. Finally, they were asked to describe themselves and how they would imagine they would act as a caregiver for a relative.

Before entering the field of study, the first author took steps to explicate and examine their preconceptions (Charmaz, 2014). This was done by writing down the expected findings in relation to the research questions and participating in a transparent dialogue with the coauthors. Furthermore, the authors studied the medical field and specifically the neurorehabilitation field and its historical origins (Bystrup et al., 2018). This is, according to Bourdieu, a way of creating a distance to what is otherwise naturalized in the field (Bourdieu, 1986).

To investigate the encounters between health professionals and caregivers, an observation guide and a semistructured interview guide were constructed, based mainly on Bourdieu's theory, describing how different practices of CHC may look in the field and how different resources are deployed, recognized, and rewarded (Bourdieu, 1977, 1980, 1986). During the data collection process, researchers attempted to keep an openminded approach to stay attuned to and observe real-world interactions.

\section{Empirical Data}

The number of observations and interviews varied due to the availability and accessibility of both caregivers and patients.

\section{Data Analysis}

Field notes were written during the observations, and these were expanded into full text as soon as possible afterwards. The interviews were recorded and also transcribed.

In the coding and analysis procedure, the first transcriptions of the interviews and observation notes were coded line by line by the first author (Rønn-Smidt), and in parallel, selected transcriptions were coded separately by two of the authors (Shim and Fitzsimmons). Several codes emerged, namely "negotiating," "expressing worry or hope," "setting the stage," "sharing outside life," and "asking questions." The three coding authors then discussed the codes to make them as many-faceted and fitting as possible. Rønn-Smidt and Fitzsimmons wrote memos during the coding process to check that all authors understood the codes in 
the same way and to include all authors' perspectives in embracing the complexity of the data as much as possible. The codes were sorted and assembled into overall bundles using NVivo 11. The bundles received the overall headings of caregiver strategies, knowledge of value, and how the caregivers appear. Finally, the bundles were reread and the headings refined, becoming empirical categories: (a) strategies of collaboration (emotion management, shared language, shared information, asking the right questions), (b) negotiating knowledge (what knowledge is of value?), and (c) appearance (showing the right face).

The categories of caregiver strategies were broad, and it was possible to divide these into several smaller bundles, which then became the study's empirical subcategories: emotions, language, information, and questions. Using the numerous memos generated by the authors, the codes in each category were described and summarized into a condensed text, which was related to the overall transcriptions to secure the coherence to the overall understanding of the empirical data. The text was focused according to the research questions on how to understand the role played by the patient's caregiver and how inequality is produced in the encounter with professionals, and from the data collected, quotations were chosen to illustrate the findings in the Results section.

Following the qualitative data coding and analysis, some examples of different caregiver types were constructed to further elucidate the use of CHC. These types were not generated from and did not refer to individual participants but rather were constructed by the first author, inspired by Weber's (Barbalet, 2008; Weber et al, 1978) and Højrup's (2010) concept of “ideal types." According to Højrup, summarizing important data transversely to the individual interviews and observations is one tool to create a meaningful and coherent picture of real-world phenomena. However, the examples here do not claim to cover the full range of different caregiver types. We are only presenting some examples that emerged in our investigation to facilitate further reflection.

\section{Results}

In this section, we present the main findings organized according to categories and subcategories.

\section{Strategies of Collaboration}

The data revealed that strategies of collaboration are differentiated by how caregiver strategies are enacted. The study shows that to make the collaboration flow easily, there has to be a balance in an individual's behavior: On one hand, they must fight for the patient to receive attention and to get the best examinations and treatment, but on the other hand, they must be aware of how their actions can be adjusted according to the situation. Caregivers' strategies are often conducted implicitly and not described or verbalized. The professionals describe how they consider some of the caregiver strategies positive, making communication and cooperation flow more easily while creating a mutual sense of understanding and the sense that both the professional and the caregiver are doing their best under daunting circumstances. The study reveals that the formal meetings that occur between health professionals and the caregivers with more positive collaboration strategies often last longer and the caregiver opinions are more likely to be taken into consideration by the health professionals.

\section{Emotion management}

It can be an emotional experience to care for a person who has suffered a stroke. The caregivers talked about feelings of sorrow and loss and of how everyday life was turned completely upside down. The data revealed that when the caregivers managed to retain some element of control over their emotions, this was perceived as "positive" by the health professionals and was considered beneficial for collaboration. Some caregivers were able to manage their emotions. For instance, John, who was the husband of a woman with a severe brain injury, was held to the rule of emotion: that he needed to be calm and competent and not angry or irritable. 
He explained how he was aware of this and described how he chose to behave: "I do get very irritated and angry, but I hide it away. I am not angry with the everyday professionals. They can’t help it.”

He was aware of the power the health professionals actually exert in the interactions, and he pointed at the importance for the caregiver, through the interaction, to maintain some level of emotional control. John exemplified this "emotional work": He was not only hiding his anger, but he was also trying to feel no anger toward the professionals he met ("They can't help it"). In other words, not only did he change his mode of emotional expression, but he also tried to hide his actual feelings. Yet by describing his anger with "the System," he was able to remove the anger from the actual interaction. He stated that he was maintaining good relationships with the staff, and when he sensed his tone was becoming too harsh, he softened things up by using humor or commending the professionals.

Based on the study, healthcare professionals varied widely in their assessment of whether caregivers were helpful collaborative partners or constituted yet another "work task." As one of the health professionals explained, "...when the caregivers are so much in a crisis. Sometimes they are almost the biggest assignment." This professional described how a caregiver not following the tacit emotional rules would bring their feelings/emotions (i.e., their own sorrow and anger) to the interaction, which often not only consumed a lot of the professional's time but also created a sense of hopelessness for the patients, caregivers, and health professionals. She described how this was not at all beneficial for the rehabilitation process.

For example, Jane, the wife of Joe, who had a severe brain injury, was very focused on her own crisis. She had a significant need to talk about her own situation and the impact on the family as a whole. Her children were both over 30 .

It is also the children. They cry when I talk to them on the phone. We will never get our life back.... This is far the worst with this disease. If you have another disease you can at least talk together. With this you are just left out.

One of the health professionals described her behavior: "She is very worried and weeping. That does not help at all." The analysis reveals how the emotions are presented in and significant to the interaction between caregiver and health professionals, and subsequently how the professionals then label the caregiver. Some caregivers sensed and acted on the unspoken "emotional rule," controlling and transforming their emotions so that they retained power and positively impacted the interaction.

\section{Shared language}

Shared language seems to be an important theme in the communication between caregivers and health professionals. Observations showed that some caregivers managed to listen to the information provided by the professionals and were able to remember and use the "right" or preferred terms in later communication. One example from a formal meeting between the caregiver John and the health professionals shows how John managed to do this:

[The doctor] says that Elin's bite plate is gone missing. John adds that he remembers that she had it when she was transferred from [acute hospital]. He explains what kind of bite plate Elin has, and that he also knows they [professionals at the acute hospital] kept the cast, because they told him they would.

This led the health professionals at the meeting to discuss how to contact the other hospital and to start the process of constructing a new bite plate.

Another caregiver explained in an interview that he found it difficult to join in the dialogue, and observations of meetings in which he participated showed that communication generally proceeded in only one direction. 
The health professionals quickly recognized him as a caregiver who was unfamiliar with medical terms or did not engage using many words and who needed help. Instead of a flowing dialogue, the communication was driven and controlled by the professionals, who delivered information about what was happening and what decisions had been made. The caregiver did not ask many questions or offer additional information about the patient's outside life; thus, he was not expected to contribute, and he did not do so.

This quote is from a premeeting where only health professionals were present: "The main thing is that Chris is informed about the rehabilitation and what the consequences are... I don't think Chris has any interest in the details, but cares more about how Rose is doing."

The subsequent short meeting with Chris involved very direct information given by the doctor. After each piece of information, Chris was asked if he had any questions, but he had none. After the meeting, Chris described how he found it difficult to know what to say: "I don't know [what to say]. I guess it is okay. I know nothing about things like that. I just don't think she is getting any better."

One of the health professionals said after the meeting with Chris,

...if it was a family with some more resources, this would never go ahead without much more complaining. But Chris does not say anything. He does his best, but he does not understand much of it. And he does not know what to do. We can't expect him to do much, we just have to inform him about how things are.

The current study shows that the language used in a hospital setting is often unfamiliar to caregivers, and shared language becomes capital in the communication between health professionals and caregivers. Interestingly, some caregivers were able to learn the appropriate medical language and knowledge during the rehabilitation process.

\section{Shared information}

The study also revealed that as part of the collaboration, the caregivers contributed personal information about the patients who could not speak for themselves. John represents a caregiver with a sense of what type and what quantity of information about his wife's life would be relevant to the professionals and would therefore be useful to exchange. When he was asked at a meeting with the health professionals, he described his wife's habits in her everyday life:

She loves hot water, and she is very sensitive to cold. She hates when it is cold outside. Elin is also a super B-person. Likes to sleep late, and she really needs her sleep. ...And she does not handle pain very well, just cutting herself a bit with a knife...

While John was describing Elin, the professionals nodded, saying, "hmmm" and "yes." They showed that they were listening, but they did not comment. They wrote notes while John was speaking. They asked elaborating questions about Elin's personal hygiene routines, and John supplied additional and thorough answers, explaining that she used to spend a lot of time on that: "Elin used to care a lot about plucking her eyebrows and coloring her grey hair. And absolutely no hair in her armpits! She uses plenty of different things, cosmetics. She spends time on that." The professionals then suggested that her own cosmetics should be brought in because it might create some recognition in her brain, arguing that in rehabilitation, recognition can have an impact on the patient's recovery even if it is not medically significant.

A second example of an elaboration of personal attributes involved the caregiver Jane and the friend she had brought for assistance. Jane had difficulty with the exchange. Observations of the formal meeting between health professionals and Jane and her friend revealed that when Jane and her friend provided additional information throughout the meeting, the professionals did not ask any elaborating questions: 
Friend: He biked to his parents' in South Jutland. At that time, we all agreed he couldn't be right in his head. (laugh)

Jane: I don't think I got to tell you that Joe does not like cheese or herring?

Information like this emerged several times during the meeting and seemed to do so without relevant context. At one point, a professional said, "Joe did bring all his papers here. Also the description you made of him, Jane, when he was first admitted.”

Mostly, however, the study showed that in response to information offered by Jane and her friend, the professionals just said, "yes" or "no" and then continued on with what they had just been talking about, which was solely related to medical information. As one of the professionals stated in an interview, the professionals often had to keep the conversation on the topic of what they regarded as relevant subject matter and that nonrelevant input from the caregiver did not create a shared dialogue.

These examples from the study illustrate that there was no clearly defined recipe for what information caregivers could offer that would make a recognized contribution to the rehabilitation process. Some elements of personal and social details might be important, and the caregiver had to sense which information was received positively and which was not. The power dynamic between the health professionals and caregivers was imbalanced, and the caregiver had to try to adjust it.

\section{Asking the right questions}

Observations showed that the caregivers were often encouraged to ask questions, should they have any, but it also showed that in practice not all questions facilitated the collaboration process. When a caregiver asked elaborating questions, this demonstrated interest and understanding. If the caregiver then acknowledged the professionals' answers, this signaled a shift of power back to the professional and constituted an acknowledgement of their professional knowledge and judgment. Some questions, therefore, elicited better answers than others. When the professionals were asked about medical conditions and terms, they gave more thorough and longer answers than if the questions were more subjective or concerned with feelings and qualitative changes. The following example is from a formal meeting between Jane and health professionals:

Health professional [explaining about the patient's swallowing function]: We still don't know if Joe will succeed in swallowing in the right way, but that is pretty crucial. We tested his swallowing with a fiberoptic endoscopic evaluation of swallowing, and there is still some paralysis in his throat. And the second time we checked, there was still some swelling.

Jane: How do you see the difference between paralysis and swelling?

Health professional: That is a very good question. [The professional explained the difference thoroughly.]

During another meeting between John and the professionals, John asked a question about some observations he had made:

John: She looks more relaxed, more at ease. As if she is more self-sustaining. She also had a lot of saliva before. She can often dribble when she is asleep. I don't know...?

Health professional: That is rather common. Lots of people do that, when they are fast asleep.

The date show that questions and answers construct the dialogue and allow the communication to flow, but there is a balance as to how many questions are beneficial to the dialogue. The three examples below illuminate this. 
At this meeting, John asked only three questions, two of which were questions asking for clarification about medical subjects the health professionals were talking about. This led to the professionals elaborating on their explanations, which supported the ongoing dialogue. John asked an additional question, which initiated a topic of conversation. It was a medical question, which demonstrated that he was observant and knew what was occurring in the ward. The professionals asked John three overall questions about his wife and her life before the stroke, and John used this opportunity to give his opinion about his wife, her condition, and the ward and rehabilitation.

At this meeting, Jane asked 10 questions. She brought a notebook with the questions written down in advance. She wanted to ask about the details she had observed or thought about, and she pointed out many different issues. The communication became fragmented and interrupted, without much elaboration or dialogue. Jane only asked one elaborating question about what the professionals had said. The professionals asked her two questions about her and her husband before his stroke. She answered briefly and they did not ask further questions.

At this meeting, Chris had three questions about his wife and her rehabilitation: Was she getting better? Could she come home? How long would it take? To each question, the professionals did not have a concrete answer. They asked him a few questions about his wife and their life before the stroke, and he answered briefly. The meeting became mostly the professionals giving information. They asked Chris several times if he had any questions, but he had no further questions. The meeting ended 15 min ahead of schedule.

Observations of the meetings between professionals and caregivers showed that too many questions interrupted the dialogue and that this led to the professionals limiting their replies or avoiding answering the questions.

\section{Negotiating Knowledge}

\section{What knowledge is of value?}

The study shows that in the encounter with caregivers, the professionals apply their medical knowledge related to their professional experience. In the interviews, several professionals said that within the healthcare system, the descriptions of the medical condition and the professionals' observations are regarded as the central and most important information. Observations during the study indicate that the body is mostly regarded as a medical object that has certain impairments and can achieve improvements. In contrast, the caregivers tried to share their personal knowledge about their relative, and that knowledge is interwoven with emotions and subjectivity related to a shared life history. This is exemplified in this exchange during a meeting between Chris and the health professionals at the hospital:

Health professional: Rose is able to swallow and to cough. And we are training her in preparation to do without the tube. If everything goes according to plan, she will be able to do with a plain tube. That is fairly realistic.

Chris: Will she be able to eat?

Health professional: We can start letting her taste different things, that might wake her up. I do have my doubts that she will be able to know how to eat... But the sense of tasting can be very good for her.

Chris: It could be a goal for her to have rice pudding for Christmas.

Health professional: Yes, but we can't just pour it down her throat. 
Chris explained afterward that he wanted Rose to have something that she likes and that reminds her of Christmas, but observation shows that according to the professionals, communication should be about the medical aspects of swallowing.

We also observed that the caregivers often noticed or valued different things than the professionals did, and the caregivers struggled to bring these to the professionals' attention. For instance, John described the following at a meeting:

I noticed that Elin's pulse was much lower than usual. That was nice to see. And that she moved her head. I haven't seen it like that before... She sometimes tries to communicate, I am sure of that. That it is not just mouth sounds. She actually tries to say something.

The healthcare professionals did not respond to this but went on talking about other things, and thereby they dismissed John's observations.

In summary, our analysis seems to indicate that there is a mismatch between professionals' and caregivers' knowledge. On one side, there is the professionals' medical knowledge (medical condition, swallowing, cough), treatment plans (prognosis), the body as an object (impairment, improvement), technology of treatment (e.g., tubes) and on the other side, caregivers' knowledge, presented as a personal knowledge of everyday things (like he/she was before), how the patient enjoys eating and knowing it is Christmas, a sense that the person is still in there (he/she is trying to move, trying to speak, is having emotional reactions). Moreover, some caregivers try to negotiate the professional encounter and share the type of knowledge that they perceive to be valuable to the professionals.

\section{Appearance}

\section{Showing the right face}

The data reveal that the caregiver's appearance is part of the interaction between the caregiver and the health professionals. In our interviews with John, he said he was very conscious about how he appeared in the eyes of the professionals and other people around him. He was always well groomed, the house was kept clean and tidy, and he showed control over himself, his family and his finances. He showed an interested attitude at the meetings: being friendly, sitting up straight, hands on the table, and looking people in the eye. John also praised the hospital at the formal meetings: "I have felt much better since Elin came to this hospital... We [the family] are so happy she is here. We hoped for this, but we didn't talk about it, afraid to be disappointed."

Another observation and interview showed that Jane experienced the rupture in her everyday life as overwhelming. It was important for her to communicate this and to show through her appearance the difficulties and the terrible situation the family found itself in, pushing the professionals for help. As she described it herself, "I don't have the energy to be concerned about myself and how I appear. And it does not matter. They [the professionals] know I am in a terrible situation."

When interviewed, Chris did not reflect on his own appearance. To him, it was important to show the professionals that he was a responsible caregiver by showing up at the hospital every week (he had to take the bus for $3 \mathrm{hr}$ to get there) and participating in the meetings. It was, however, hard for him to know what to do. After one observation on the ward, he described how he felt that he was just standing there, really wanting to leave. During meetings, Chris appeared sad and uncomfortable, looked down at the table or at the floor, and avoided eye contact. Altogether, these examples show different strategies with regard to appearance. Some of the caregivers considered their appearance and demonstrated embodied knowledge of how to participate as caregivers, while others did not as much. Based on the data analysis, three caregiver types were constructed (see Table 2). 
Table 2. Caregiver Types

\begin{tabular}{|c|c|c|c|}
\hline \multirow{2}{*}{$\begin{array}{l}\text { Collaboration } \\
\text { strategy }\end{array}$} & \multicolumn{3}{|c|}{ Caregiver type } \\
\hline & Proactive & Persistent & Deferential \\
\hline \multicolumn{4}{|l|}{ Communication } \\
\hline $\begin{array}{l}\text { "Shared language"; } \\
\text { "asking the right } \\
\text { questions" }\end{array}$ & $\begin{array}{l}\text { Flowing dialogue: listens } \\
\text { and uses medical } \\
\text { language }\end{array}$ & $\begin{array}{l}\text { Disrupted dialogue: many } \\
\text { questions and repetitions; } \\
\text { doesn't listen and uses } \\
\text { everyday language }\end{array}$ & $\begin{array}{l}\text { Little dialogue: mostly } \\
\text { one-way information } \\
\text { from professionals to } \\
\text { relative; listens, but does } \\
\text { not say much and uses } \\
\text { everyday language }\end{array}$ \\
\hline $\begin{array}{l}\text { "Shared information"; } \\
\text { "negotiating knowledge" }\end{array}$ & $\begin{array}{l}\text { Contributes with what the } \\
\text { health professionals } \\
\text { consider useful } \\
\text { information; insists on } \\
\text { having relevant } \\
\text { knowledge }\end{array}$ & $\begin{array}{l}\text { Contributes much } \\
\text { information that the } \\
\text { health professionals } \\
\text { consider irrelevant; has } \\
\text { difficulties in structuring } \\
\text { knowledge }\end{array}$ & $\begin{array}{l}\text { Does not contribute much } \\
\text { information or } \\
\text { knowledge; does not } \\
\text { believe they have any } \\
\text { relevant or useful } \\
\text { knowledge }\end{array}$ \\
\hline "Shared language" & $\begin{array}{l}\text { Talking about the patient's } \\
\text { medical conditions; the } \\
\text { body as an object }\end{array}$ & $\begin{array}{l}\text { Talking about the patient's } \\
\text { likes and dislikes; the } \\
\text { body as a subject }\end{array}$ & $\begin{array}{l}\text { Asking health } \\
\text { professionals about } \\
\text { improvement; does not } \\
\text { speak about own } \\
\text { observations }\end{array}$ \\
\hline \multicolumn{4}{|l|}{ Appearance } \\
\hline \multirow[t]{2}{*}{$\begin{array}{l}\text { "Showing the right } \\
\text { face" }\end{array}$} & $\begin{array}{l}\text { Showing interest and the } \\
\text { will to make the best of it }\end{array}$ & $\begin{array}{l}\text { Partly putting good } \\
\text { behavior aside for the } \\
\text { sake of the greater cause; } \\
\text { having one's rights } \\
\text { fulfilled }\end{array}$ & Pleading for help \\
\hline & $\begin{array}{l}\text { Attention to own } \\
\text { appearance; well } \\
\text { groomed, nice clothes }\end{array}$ & $\begin{array}{l}\text { No attention to own } \\
\text { appearance; usually } \\
\text { better groomed }\end{array}$ & $\begin{array}{l}\text { No attention to } \\
\text { appearance; clothes a bit } \\
\text { shabby, in need of a } \\
\text { haircut }\end{array}$ \\
\hline \multicolumn{4}{|l|}{ Attitude } \\
\hline \multirow[t]{2}{*}{ "Emotion management" } & Showing self-control & Chaotic & Emotional \\
\hline & Keeps focus on the patient & Focuses on self and family & $\begin{array}{l}\text { The professionals choose } \\
\text { the focus }\end{array}$ \\
\hline
\end{tabular}

To summarize the empirical findings of this study, the constructed types of caregivers (Table 2) illustrate how different, and often unconscious, strategies influence the encounter between patients, caregivers and health professionals in subtle ways. Related to our overall research question on how to develop a broader understanding of the role played by the patient's caregiver, the empirical categories show that the caregivers' ability to read the situation, and on this basis, adjust their emotions, verbal communication, and appearance, are found to be important for how caregivers are perceived as appropriate caregivers by the professionals. The caregivers' ability to choose which information and knowledge to provide and which and how many questions to ask signals both their ability to be an important collaborator to the professionals, and also shows their respect and interest in the rehabilitation professionals' competencies. 
The data in this study illuminate that the ability to provide information to the professionals and value them is "a balancing act" as the position of being a caregiver hangs between taking action and accepting the competencies and actions of professionals. How to best manage this position as a caregiver is not explicit in the interactions between relatives and professionals; thus, the caregiving role is conditioned by the different resources accessible to the caregiver and by how these resources are perceived as capital by the professionals. Based on our research question, this study also shows how inequality not only emerges due to the resources of caregivers, but is also produced and constituted in the encounter with professionals.

\section{Discussion}

This present study shows that caregivers have a very challenging and dynamic role to play when acting as a proxy for their loved one (i.e., the patient) who has suffered a traumatic brain injury after a stroke. Caregivers often reflect upon and create a "role" as a caregiver and are very aware that they have to aggressively advocate for their loved ones. The caregivers generally describe a sense of great responsibility, being the one their loved ones depend upon, and they try to fulfill this position in the best way they can.

This study investigated different strategies for collaborative participation within the professional-caregiver dyad during the rehabilitation process. These strategies are often implicit, unconscious, and not rationally chosen but are rather connected to what Bourdieu describes as a person's habitus. That is, a bodily sense of how to "play the game" (Bourdieu \& Wacquant, 1992; Hillier \& Rooksby, 2005) using the capital available. Caregivers use various strategies to do this, and this study sheds light on the specific skills they must possess in relation to communication, knowledge, and appearance to be recognized as a competent and collaborative caregiver. The "proactive," "persistent," and "deferential" caregiver styles all seemed to play a unique role in the healthcare system (i.e., the healthcare "game"). CHC theory combined with our findings allows for a deeper and more nuanced understanding of how to recognize the potential inequality constructed in the professional-caregiver dyad encounter.

We observed that some caregivers were considered troublesome by the health professionals, and this seemed to be based on the strategies the caregiver chose to employ. Some caregivers would disrupt the flow and ease of communication. As Lindhardt (2008) explained, health professionals tend to avoid these caregivers because of the extra burden they represent in an already stressful job. But at the same time collaboration is extremely important. According to McConnell (2017), caregiver collaboration is both demanded and rewarded in the encounter with health professionals. He demonstrated how caregivers' experience, knowledge, and, not least, trust in the health system contribute both positively and negatively to the collaboration.

In our study, health professionals described how they work to adapt interactions to the patient's/caregiver's resources. The health professionals described a "good" patient or relative as one with "good" resources. What it takes to be "good" or having "good" resources seems to be naturalized in the clinic. This is similar to the findings in Sointu (2017), who highlighted the subtle yet powerful ways in which inequality becomes entrenched due to professionals' ideas about "good" and "bad" patients. But at the same time, we argue that resources are not stable across time and fields. Resources have to fit current values in a specific field, and they become capital if there is a "market" for them (Bourdieu, 1977, 1986).

This is also the case in this study, where we observe that the meeting between professionals and patients/caregivers was constituted according to a specific set of values and specific logic in the neurorehabilitation field. These values and logical systems may also be culturally influenced. In Denmark, the health system, today known as the Danish Public Health Authority, was established in the middle of the 18th century, primarily to use isolation and treatment to prevent the spread of infectious diseases (Hjortbak, 2013). For many years and into the twentieth century, the three main health ideals were "light, air, and cleanliness" (Schmidt \& Kristensen, 2004). To this was added a "good" patient (or caregiver), one who did not ask any 
questions but just did as she or he was told. Today, the healthcare system in Denmark, as in many other Western countries, employs a more patient-centered approach (World Health Organization, 2000). As a consequence, patients are expected to actively participate in the prevention of disease as well as in their own treatment and rehabilitation (Hjortbak, 2013). Patient and caregiver participation positively influences the effectiveness of rehabilitation (Cicerone et al., 2008; Doig et al., 2009; Kristensen et al., 2016; Leach et al., 2010). It also provides motivation and opportunity for mutual understanding between patient and professional (Dubbin et al., 2013).

This value system is confirmed in the present study, where the professionals described a "good" caregiver as one who takes responsibility in the rehabilitation process, participates, communicates, takes action, and so on. The professionals also responded to the caregivers' appearance and ability to control their emotions, as described by Hochschild's (1979) concept of "emotional work." Our analysis in this study shows how some strategies are explicitly highlighted or observed by professionals and caregivers as creating an "ease" in the clinical encounter. This ease is translated to "good resources" and shared understanding, verbalized in an interview with one health professional as "pulling in the same direction." Our study shows that in return for paying this kind of capital, the caregiver is given the chance to enter the dialogue as a valued collaborator.

When professionals were asked if there are any caregivers that they find easier/more difficult to collaborate with, they mostly answered that there were none. They claimed that different caregivers simply present different challenges. This statement reflects the politics of the welfare state in Denmark, which is built on a platform of equality. In the healthcare system there is the concomitant ethical value that every person is treated equally, and in consequence of this ideal of equality, an admission of inequality is by definition "unprofessional." We argue that this might cover up what is presented in this study, namely, that some caregiver-professional dyads find it easier than others to collaborate, and that this relative ease or difficulty is not only related to standardized socioeconomic factors but is much more complex and is related to the professionals' incorporated practices. Other studies have also discussed this inequality in healthcare in Denmark (Larsen et al., 2013; Larsen \& Esmark, 2013).

Although we acknowledge the limitations of a qualitative study and the relatively small number of participants in the sample, these results reveal important new findings regarding the collaborations between caregivers and health professionals, which is an important focus for families, clinicians, governmental agencies, and international health organizations. Our findings are in many ways consistent with the studies of Dubbin et al. (2013) and Chang et al. (2016), which showed how the use of the concept of CHC can illuminate how health capital is conceived and constructed in the actual encounter between health professionals and caregivers. Furthermore, this study highlights how the idealistic value of treating every patient and caregiver "equally" may conceal the machinations that actually go on between caregivers and health professionals and may therefore deprive professionals of the possibility to reflect on, recognize, and manage this in their current practices.

Seen from this perspective, the study shows that any meeting between caregivers and professionals has its own logical system, which determines what caregivers should say, what information to bring and share, how many questions to ask, and how one earns the opportunity to be recognized as a "good" caregiver. The professionals often ask the caregiver if they have any questions, but this study points out that caregivers must become part of the dialogue before they can engage in productive questioning. The study shows that at the same time, the professionals should adapt their practice to fit the specific field, and we argue that the professionals' modes of engagement with the caregiver are very much formed by their (often unspoken) dispositions of how to present as a worthy and recognized expert professional. This means prioritizing medical knowledge as the highly valued commodity in the highly specialized field of neurorehabilitation. Regarding the caregiver, the professionals stated in the interviews that they often feel as if the collaboration depends on their own personal experiences and values. They do not recall learning professional-caregiver 
collaboration as part of the curricula during their professional training. As a result, issues in relation to the caregivers may come to rest on uneven ground, and the professionals might be more inclined to dismiss what is conceived important to caregivers.

There are several limitations of this study. For example, study participants did lack cultural and ethnic diversity, so we recommend further studies relating to the specific finding with larger sample sizes and a more purposeful diversity among the caregivers. This topic could also be investigated further with a focus on the habitus and $\mathrm{CHC}$ of the health professionals in the study. This could illuminate how their habitus influences the professional-caregiver relationship.

\section{Conclusion}

Based on the concept of $\mathrm{CHC}$, this study shows how different caregivers are differently positioned as collaborators according to their habitus and how their different strategies are perceived as capital in the healthcare field. Inequality in healthcare is well known, but this study shows that interactions with healthcare professionals also produce inequality. Identifying different types of caregiver and recognizing how the field (and their own habitus) sets certain rules for how to "play the game" might help health professionals to better support the caregiver and thereby promote important collaboration.

\section{References}

Abel, T. (2008). Cultural capital and social inequality in health. Journal of Epidemiology and Community Health, 62, 1-5.

Altin, S. V., \& Stock, S. (2016). The impact of health literacy, patient-centered communication and shared decision-making on patients' satisfaction with care received in German primary care practices. BMC Health Services Research, 16, 1-10.

Arbuthnott, A., \& Sharpe, D. (2009). The effect of physician-patient collaboration on patient adherence in non-psychiatric medicine. Patient Education and Counseling, 77, 60-67.

Barbalet, J. M. (2008). Weber, passion and profits: "The Protestant ethic and the spirit of capitalism" in context. Cambridge University Press.

Bourdieu, P. (1977). Outline of a theory of practice. Cambridge University Press.

Bourdieu, P. (1980). The logic of practice. Standford University Press.

Bourdieu, P. (1986). The forms of capital. In J. Richardson (Ed.), Handbook of theory and research for the sociology of education (pp. 241-258). Greenwood Press.

Bourdieu, P., \& Wacquant, L. J. D. (1992). An invitation to reflexive sociology. University of Chicago Press.

Bystrup, M. R., Larsen, K., Hindhede, A. L., Pallesen, H., Aadal, L., \& Feiring, M. (2018). Outline of the history of neurorehabilitation in Denmark: A sociological perspective. Praktiske Grunde: Nordisk Tidsskrift for Kultur-Og Samfundsvidenskab, 2018(3-4), 5-28.

Chang, J., Dubbin, L., \& Shim, J. (2016). Negotiating substance use stigma: The role of cultural health capital in provider-patient interactions. Social Health and Illness, 38(1), 90-108.

Charmaz, K. (2014). Constructing grounded theory (2nd ed.). Sage.

Chung, P. (2013). Professionals partnering with family carers in home-based activity for those with dementia. World Federation of Occupational Therapists Bulletin, 67, 9-16. 
Cicerone, K. D., Mott, T., Azulay, J., Sharlow-Galella, M. A., Ellmo, W. J., Paradise, S., \& Friel, J. C. (2008). A randomized controlled trial of holistic neuropsychologic rehabilitation after traumatic brain injury. Archives of Physical Medicine and Rehabilitation, 89, 2239-2249.

Cloninger, C. R. (2011). Person-centred integrative care. Journal of Evaluation in Clinical Practice, 17, 371-372.

Collyer, F. M., Willis, K. F., \& Lewis, S. (2017). Gatekeepers in the healthcare sector: Knowledge and Bourdieu's concept of field. Social Science \& Medicine, 186, 96-103.

Crawford, J., \& McKee, K. (2018). Hysteresis: Understanding the housing aspirations gap. Sociology, 52(1), 182-197.

Doig, E., Fleming, J., Cornwell, P. L., \& Kuipers, P. (2009). Qualitative exploration of a client-centered, goaldirected approach to community-based occupational therapy for adults with traumatic brain injury. American Journal of Occupational Therapy, 63, 559-568.

Dubbin, L. A., Chang, J. S., \& Shim, J. K. (2013). Cultural health capital and the interactional dynamics of patient-centered care. Social Science \& Medicine, 93, 113-120.

Flachs, E., Eriksen, L., Koch, M., Ryd, J., Dibba, E., Skov-Ettrup, L., \& Juel, K. (2015). Sygdomsbyrden $i$ Danmark [Burden of disease in Denmark]. Sundhedsstyrelsen.

Formosa, C. (2015). Understanding power and communication relationships in health settings. British Journal of Healthcare Management, 21, 420-424.

Gabay, G. (2015). Perceived control over health, communication and patient-physician trust. Patient Education and Counseling, 98, 1550-1557.

Gagné, T., Frohlich, K. L., \& Abel, T. (2015). Cultural capital and smoking in young adults: Applying new indicators to explore social inequalities in health behaviour. European Journal of Public Health, 25, 818-823.

Hillier, J., \& Rooksby, E. (Eds.). (2005). Habitus: A sense of place (2nd ed.). Routledge.

Hjortbak, B. (2013). Sundhedsvæsenet på Tværs [Across health service] (2nd ed.). Munksgaard.

Hochschild, A. R. (1979). Emotion work, feeling rules, and social structure. American Journal of Sociology, $85,551-575$.

Højrup, T. (2010). Det glemte folk: livsformer og centraldirigering [The forgotten people: Life forms and central routing]. Museum Tusculanum.

James-Hawkins, L. (2014, May 1-3). Cultural health capital and the contraceptive medical encounter [Paper presentation]. Population Association of America Annual Meeting, Boston, MA, United States.

Khabarov, D., Dimitropoulos, G., \& McGillicuddy, P. (2015). Qualitative study: Exploring the experiences of family caregivers within an inpatient neurology and neurosurgery hospital setting. Health \& Social Work, 4O(4), 290-297.

Kompetencecenter for Epidemiologiog Biostatistik Nord. (2014, April 28). Dansk Apopleksiregisterz: Årsrapport 2013. https://www.sundhed.dk/content/cms/69/4669 dansk-apopleksiregister aarsrapport 2013 kommenteret- off 28042014.pdf

Kristensen, H. K., Tistad, M., Von Koch, L., Ytterberg, C. (2016). The importance of patient involvement in stroke rehabilitation. PLOS ONE 11, 1-14

Larsen, K., Cutchin, M., \& Harsløf, I. ( 2013). Health capial: New health risks and personal investments in the body in the context of changing nordic welfare states. In Harsløf, I., Ulmestig, R. (Eds.), Changing 
social risks and social policy responses in the nordic welfare states (pp. 165-188). Palgrave Macmillan.

Larsen, K., \& Esmark, K. (2013). Velfærdsstat, Sundhed og Kroppe under Forandring-norske og danske studier [Welfare state, health and changing bodies - Norwegian and Danish studies]. Praktiske Grunde: Nordisk Tidsskrift for Kultur-Og Samfundsvidenskab, 2013(1-2), 5-14.

Lauvli Andersen, K., Strøm, A., Korneliussen, K., \& Solveig Fagermoen, M. ( 2016). Family caregivers to a patient with chronic heart failure living at home: "Co-workers" in a blurred health care system. Norwegian Journal of Clinical Nursing / Sykepleien Forskning, 11(2), 158-165. https://pdfs.semanticscholar.org/4afb/d81369d9a9145ac160378dd99b5dac5dbee8.pdf? ga=2.21101 $\underline{6213.1057990933 .1586867601-589478301.1560368060}$

Leach, E., Cornwell, P., Fleming, J., \& Haines, T. (2010). Patient centered goal-setting in a subacute rehabilitation setting. Disability and Rehabilitation, 32, 159-172.

Lindhardt, T. (2008). Collaboration between caregiver of frail elderly patients and nursing staff in acute hospital wards. Scandinavian Journal of Caring Science, 24, 29-36.

Madden, E. F. (2015). Cultural health capital on the margins: Cultural resources for navigating healthcare in communities with limited access. Social Science \& Medicine, 133, 145-152.

Madden, E. F. ( 2018). Healthcare workers mobilising cultural health capital to assist socially marginalised patients. Health Sociology Review, 27(2), 214-228.

McConnell, W. R. ( 2017). Cultural guides, cultural critics: Distrust of doctors and social support during mental health treatment. Journal of Health and Social Behavior, 58(4), 503-519.

Ministy of Health and Health Promotion. (2015). [National programme for quality in the Healthcare System 2015-2018] (in Danish).

Missinne, S., Neels, K., \& Bracke, P. (2014). Reconsidering inequalities in preventive health care: An application of cultural health capital theory and the life-course perspective to the take-up of mammography screening. Sociology of Health and Illness, 36, 1259-1275.

National Board of Health. (2011). [Brain injury: A health technology assessment] (in Danish).

National Center for Interprofessional Practice and Education. 2018. Defining the field. https://nexusipe.org/informing/defining-the-field

O’Keeffe, M., Cullinane, P., Hurley, J., Leahy, I., Bunzli, S., O’Sullivan, P. B., \& O’Sullivan, K. (2016). What influences patient-therapist interactions in musculoskeletal physical therapy? Qualitative systematic review and meta-synthesis. Physical Therapy, 96, 609-622.

Oliveira, V. C., Refshauge, K. M., Ferreira, M. L., Pinto, R. Z., Beckenkamp, P. R., Negrao Filho, R. F., Ferreira, P. H. (2012). Communication that values patient autonomy is associated with satisfaction with care: A systematic review. Journal of Physiotherapy, 58, 215-229.

Oncini, F., \& Guetto, R. (2018). Cultural capital and gender differences in health behaviours: A study on eating, smoking and drinking patterns. Health Sociology Review, 27, 15-30.

Östlund, U., Bäckström, B., Saveman, B.-I., Lindh, V., \& Sundin, K. (2016). A family systems nursing approach for families following a stroke: Family health conversations. Journal of Family Nursing, 22, 148-171.

Pallesen, H. (2014). Body, coping and self-identity. A qualitative 5-year follow-up study of stroke. Disability and Rehabilitation, 36, 232-241. 
Pinxten, W., \& Lievens, J. (2014). The importance of economic, social and cultural capital in understanding health inequalities: Using a Bourdieu-based approach in research on physical and mental health perceptions. Sociology of Health and Illness, 36, 1095-1110.

Sagbakken, M., Nåden, D., Ulstein, I., Kvaal, K., Langhammer, B., \& Rognstad, M.-K. (2017). Dignity in people with frontotemporal dementia and similar disorders: A qualitative study of the perspective of family caregivers. BMC Health Services Research, 17, 1-11.

Schmidt, L.-H., \& Kristensen, J. E. (2004). Lys, luft og renlighed: den moderne socialhygiejnes fødsel [Light, air and cleanliness: the birth of the modern social hygiene],. Akademisk Forlag.

Shim, J. K. (2010). Cultural health capital: A theoretical approach to understanding health care interactions and the dynamics of unequal treatment. Journal of Health and Social Behavior, 51, 1-15.

Sointu, E. (2017). “Good" patient/"bad" patient: Clinical learning and the entrenching of inequality. Sociology of Health \& Illness, 39(1), 63-77.

Sudhinaraset, M., Treleaven, E., Melo, J., Singh, K., \& Diamond-Smith, N. (2016). Women's status and experiences of mistreatment during childbirth in Uttar Pradesh: A mixed methods study using cultural health capital theory. BMC Pregnancy Childbirth, 16, 1-12

Sullivan, M. (2003). The new subjective medicine: taking the patient's point of view on health care and health. Social Science \& Medicine, 56, 1595-1604.

Teasdale, G., \& Jennett, B. (1974). Assessment of coma and impaired consciousness. The Lancet, 304(7872), 81-84.

The Centre for the Advancement of Interprofessional Education. (1987). The definition and principles of interprofessional education. http://caipe.org.uk/about-us/the-definition-and-principles-ofinterprofessional-education

Thornquist, E. (2011). Klinik, kommunikation, information. Hans Reitzel.

Weber, M., Roth, G., \& Wittich, C. (1978). Economy and society: An outline of interpretive sociology. University of California Press.

World Health Organization. (2010). Framework for action on interprofessional education and collaborative practice. https://apps.who.int/iris/handle/10665/70185

Wynia, M. K., \& Osborn, C. Y. (2010). Health literacy and communication quality in health care organizations. Journal of Health Communication, 15, 102-115.

$\mathbb{4} \mid \mathrm{JSBHS}$

The Journal of Social, Behavioral, and Health Sciences (JSBHS), co-sponsored by the College of Health Sciences and the College of Social and Behavioral Sciences at Walden University, is a peer-reviewed, online, interdisciplinary journal focusing on theoretically-based research that addresses contemporary national and international issues. JSBHS articles include peer-reviewed research reports, brief resports, comprehensive literature reviews, books reviews, and student research. 